\title{
NSAIDs inhibit neovascularization of choroid through HO-1-dependent pathway
}

\author{
Narimasa Yoshinaga ${ }^{1}$, Noboru Arimura' ${ }^{1}$, Hiroki Otsuka ${ }^{1}$, Ko-ichi Kawahara ${ }^{2,4}$, Teruto Hashiguchi ${ }^{2}$, \\ Ikuro Maruyama $^{3}$ and Taiji Sakamoto ${ }^{1}$
}

Intraocular neovascularization is the leading cause of severe visual loss and anti-vascular endothelial growth factor (VEGF) therapy is currently performed for choroidal neovascularization (CNV). Despite its potent anti-angiogenic effect, there are concerns about its long-term safety. Non-steroidal anti-inflammatory drugs (NSAIDs) are common therapeutic agents used for treating inflammatory diseases, and their anti-stress effects are attracting attention now. We studied the effects of topical NSAIDs on CNV, focusing on anti-stress proteins. Cultured retinal pigment epithelium (RPE) cells were treated with NSAIDs: bromfenac, indomethacin, or vehicle control. Transcription factor NF-E2-related factor 2 (Nrf2) and its downstream anti-oxidant protein heme oxygenase ( $\mathrm{HO})-1$ were assessed using western blot and immunohistochemistry. As a result, NSAIDs induced translocation of Nrf2 into the nucleus and the robust expression of HO-1 in a dose- and time-dependent manner. Flow cytometric analysis revealed that bromfenac inhibited $\mathrm{H}_{2} \mathrm{O}_{2}$-induced apoptosis in cultured RPE cells. Next, we studied the effects of topical bromfenac on laser-induced CNV model in rat. The expressions of Nrf2 and HO-1, infiltrations of ED-1-positive macrophages at CNV lesions and size were analyzed. VEGF in the ocular fluid of these rats was also measured using enzyme-linked immunosorbent assay. Rats administered an inhibitor of HO-1 stannic mesoporphyrin (SnMP) were also studied. The results showed that topical bromfenac led to translocation of Nrf2 and induction of HO-1 in CNV lesions and that the number of infiltrating macrophages at the CNV lesion decreased. The sizes of CNV lesions were significantly smaller in bromfenac-treated rats than control CNV, and the effects were diminished by SnMP. VEGF increased in the ocular fluid after laser treatment and was inhibited by bromfenac and SnMP canceling these effects. NSAIDs inhibit CNV through the novel anti-stress protein HO-1-dependent pathway, indicating its potential therapeutic value for various intraocular angiogenic diseases including CNV.

Laboratory Investigation (2011) 91, 1277-1290; doi:10.1038/labinvest.2011.101; published online 27 June 2011

KEYWORDS: age-related macular degeneration; anti-VEGF; choroidal atrophy; photodynamic therapy; oxidative stress; steroid

Ocular angiogenesis such as choroidal neovascularization $(\mathrm{CNV})$ is a leading cause of severe vision loss in patients with various ocular diseases. ${ }^{1-3}$ Until recently, CNV was not a treatable condition and visual prognosis was poor. However, novel pharmacological therapies such as anti-vascular endothelial growth factor (VEGF) have revolutionized this field. ${ }^{4,5}$ Despite significant advances, there are still concerns about the present anti-VEGF treatment. Complete blocking of VEGF is a logically correct method; however, it may induce retinal damage after a long period, because VEGF is a neurotrophic factor and has an important role in the retinal development and neuroprotection. ${ }^{6,7}$ There are several reports showing that complete blocking of VEGF results in retinal degeneration in animals. ${ }^{8,9}$ Indeed, unexplainable retinal atrophy was noted in some eyes with age-related macular degeneration (AMD) treated after several years of intense anti-VEGF therapy. ${ }^{10}$

Recently, it was reported that non-steroidal antiinflammatory drugs (NSAIDs) inhibit CNV in animals and a large retrospective study found a reduced incidence of CNV in AMD patients taking aspirin. ${ }^{11-17}$ The anti-inflammatory properties of NSAIDs are believed to reside in their ability to inhibit the activity of cyclooxygenase (COX). Indeed COX2 was shown to have a pivotal role in the expression of VEGF in

\footnotetext{
${ }^{1}$ Department of Ophthalmology, Kagoshima University Graduate School of Medical and Dental Sciences, Kagoshima, Japan; ${ }^{2}$ Department of Laboratory and Vascular Medicine, Kagoshima University Graduate School of Medical and Dental Sciences, Kagoshima, Japan and ${ }^{3}$ Department of Systems Biology in Thromboregulation, Kagoshima University Graduate School of Medical and Dental Sciences, Kagoshima, Japan

Correspondence: Professor T Sakamoto, MD, PhD, Department of Ophthalmology, Kagoshima University Graduate School of Medical and Dental Sciences, 8-27-1, Sakuragaoka, Kagoshima 890-8520, Japan.

${ }^{4}$ Present address: Laboratory of Functional Foods, Department of Biomedical Engineering, Osaka Institute of Technology, Osaka, Japan.

Received 17 January 2011; revised 30 March 2011; accepted 28 April 2011
} 
a CNV animal model. ${ }^{18}$ However, NSAIDs have other biological actions that inhibit nuclear factor- $\kappa \mathrm{B}(\mathrm{NF}-\kappa \mathrm{B})$, which has a central role in the expression of various pro-inflammatory mediators. ${ }^{19}$ Nonetheless, the real mechanism whereby NSAIDs inhibit CNV is not fully understood.

Heme oxygenase-1 (HO-1) is an anti-stress protein. Not only its substrate, heme, but also various stressors such as oxidative stressors, ultraviolet irradiation, inflammatory cytokines, and heavy metals have been reported to induce HO-1 production. ${ }^{20-22} \mathrm{HO}-1$ degrades heme to carbon monoxide (CO), free iron, and biliverdin. Biliverdin is subsequently converted into bilirubin by biliverdin reductase. ${ }^{20-22}$ Bilirubin and biliverdin are potent antioxidants, and $\mathrm{CO}$ has an anti-apoptotic activity. Therefore, upregulation of HO-1 in cells makes the cells resistant to apoptosis induced by various stressors. It was recently reported that NSAIDs upregulate $\mathrm{HO}-1$ production in some types of cell. ${ }^{23-27}$ If this anti-stress effect were inducible with topical NSAIDs, it would be very beneficial to use NSAIDs for the treatment of angiogenesis, because they may inhibit both pathological angiogenesis and potential collateral damage related to treatment. This would be especially advantageous for angiogenic disorders of the central nervous system including CNV. In this study, we explore the influence of NSAIDs on the regulation of anti-stress proteins in vitro focusing on their anti-apoptotic action and further on their effects on $\mathrm{CNV}$ models in vivo.

\section{MATERIALS AND METHODS Cell Culture}

All experiments in vitro were performed using ARPE-19, a human diploid retinal pigment epithelium (RPE) cell line, which is in many ways similar to RPE in vivo (American Type Culture Collections, Manassas, VA). ${ }^{28}$ All cultures were fed twice weekly with Dulbecco's modified Eagle's medium: nutrient mixture $\mathrm{F} 12$, plus $10 \%$ (vol/vol) fetal bovine serum, $2 \mathrm{mM}$ L-glutamine, and penicillin-streptomycin at $100 \mathrm{IU} / \mathrm{ml}$. Cultures were incubated at $37^{\circ} \mathrm{C}$ in $5 \%$ (vol/vol) $\mathrm{CO}_{2}$ incubator and sub-cultured with $0.05 \%$ trypsin-EDTA (all products were obtained from Invitrogen-Gibco, Rockville, MD). Subconfluent cultures were trypsinized and seeded for the following experiments.

\section{Western Blot Analysis of NF-E2-Related Factor 2 (Nrf2) and HO-1}

ARPE-19 cells were subcultured on 6-cm tissue culture dishes. The cells were serum starved for $3 \mathrm{~h}$ and stimulated with the indicated concentration of indomethacine (Funakoshi, Tokyo, Japan), bromfenac (provided from Senju Pharmaceutical, Osaka, Japan) as NSAIDs, or dimethylsulfoxide (DMSO) as control for the indicated time. Nuclear and cytoplasmic extracts of cells were prepared using the Pierce NE-PER nuclear and cytoplasmic extraction kit (Pierce, Rockford, IL). They were subjected to $10 \%$ SDSpolyacrylamide gel electrophoresis and transferred to nitrocellulose membranes (GE Healthcare Bio-sciences KK, Piscataway, NJ) as with our previous methods. ${ }^{28,29}$ Membranes were incubated with a blocking buffer containing $1 \%$ BSA and $5 \%$ non-fat milk in $25 \mathrm{~mm}$ Tris-HCl-buffered saline with $0.02 \%$ Tween 20 (TBST), followed by incubation with the respective primary antibodies (1:200; anti-Nrf2 rabbit polyclonal antibody, 1:500; anti-HO-1 antibody, 1:200; anti- $\beta$-actin goat polyclonal antibody, Santa Cruz Biotechnology Inc., CA) in TBST containing $1 \%$ non-fat milk overnight at $4^{\circ} \mathrm{C}$. After three washes with TBST, membranes were incubated with horseradish peroxidase (HRP)-conjugated anti-rabbit IgG polyclonal antibody (Santa Cruz Biotechnology Inc.) or HRP-conjugated antigoat IgG polyclonal antibody diluted 1:3000 in TBST containing $2.5 \%$ non-fat milk for $1 \mathrm{~h}$. The membrane was washed twice, and immunoreactive bands were visualized using an ECL detection system (GE Healthcare Bio-sciences $\mathrm{KK})$. Immunoreactive bands were quantified and relative sum intensities of bands were compared using Image J Software (US National Institutes of Health).

\section{Immunocytochemistry of Nrf2 and HO-1}

Immunocytochemistry was carried out in accordance with our previous method. ${ }^{28,29}$ ARPE-19 cells were grown on culture slides and serum starved for $3 \mathrm{~h}$, then treated with the indicated concentration of indomethacin, bromfenac, or DMSO as the control for $3 \mathrm{~h}$. After treatment, slides were washed with PBS, fixed with OptiLyse C (Beckman Coulter, Miami, FL), blocked with $1 \%$ BSA in PBS containing $0.1 \%$ of triton-X100 (PBST) for $60 \mathrm{~min}$ and incubated with polyclonal rabbit anti-Nrf2 and anti-HO-1 antibody (each 1:100; Santa Cruz Biotechnology Inc.) in PBS containing 1.5\% BSA for $60 \mathrm{~min}$ at room temperature. The slides were washed with PBST, incubated with secondary antibodies, Alexa-Fluor 488-conjugated goat anti-mouse IgG $\mathrm{F}(\mathrm{ab}) 2$ fragment, and Alexa-Fluor 594-conjugated goat anti-rabbit $\operatorname{IgG} \mathrm{F}(\mathrm{ab}) 2$ fragment (each 1:400; Molecular Probes, Carlsbad, CA) for an additional $60 \mathrm{~min}$ in the dark at room temperature. Stained cells were washed, mounted with Shandon PermaFlour (Thermo Scientific, Waltham, MA), and examined with a Zeiss fluorescence microscope (Zeiss, Oberkochen, Germany).

\section{Flow Cytometric Analysis}

To analyze the cellular DNA content, the propidium iodide staining method was used as previously described. Briefly, ARPE-19 cells subcultured on 6-cm dishes at a density of $4.5 \times 10^{5}$ cells per dish and incubated with bromfenac or DMSO as a control were dissolved in medium with $1 \%$ fetal bovine serum for $24 \mathrm{~h}$. After treatment for the indicated periods, the cells were washed with PBS. The pellet was resuspended in $70 \%$ ethanol $(2 \mathrm{ml})$, and the suspension was incubated at $-20{ }^{\circ} \mathrm{C}$ for $20 \mathrm{~min}$. Cells were then incubated in the dark for $15 \mathrm{~min}$ with propidium iodide $(5 \mathrm{~g} / \mathrm{ml})$ in PBS in the presence of RNase $(5 \mathrm{~g} / \mathrm{ml})$. Then, the DNA content was 
determined $\left(2 \times 10^{4}\right.$ cells each time $)$ with a FACS analyzer (Epics; Beckman Coulter).

\section{Cell Viability Assay}

Cell viability was analyzed from mitochondrial respiratory activity measured using MTT (3-(4,5-dimethylthiazol-2yl)2,5-diphenol tetrazolium bromide) assay (Wako Chemicals, Osaka, Japan), as described previously. ${ }^{28}$ Briefly, $3.5 \times 10^{4}$ ARPE-19 cells were cultured in 24-well plates $(500 \mathrm{ml}$ medium per well) and pretreated with $2.5 \mu \mathrm{M}$ bromfenac or DMSO dissolved in a medium with $1 \%$ fetal bovine serum for $24 \mathrm{~h}$. Then, the cells were stimulated with or without hydrogen peroxide ( $500 \mu \mathrm{M}$; Merck, Darmstadt) for $15 \mathrm{~min}$ and incubated with MTT $(0.5 \mathrm{mg} / \mathrm{ml}$; final concentration) for $3 \mathrm{~h}$. Formazan product was solubilized by the addition of DMSO for $16 \mathrm{~h}$. Dehydrogenase activity was expressed as absorbance at a test wavelength of $570 \mathrm{~nm}$ and at a reference wavelength of $630 \mathrm{~nm}$. Assays were performed in triplicate and repeated three times in independent experiments.

\section{Animals}

Brown-Norway rats (7 week old male; weight 140-160 g) were purchased from Kyudo (Fukuoka, Japan), and housed in a temperature-controlled room. The animals were kept on a 12-h light-dark schedule and had free access to food and water. All animals were treated in accordance with the ARVO Statement for the Use of Animals in Ophthalmic and Vision Research.

\section{Induction of Experimental CNV}

A rat $\mathrm{CNV}$ model was made accordance to our previous methods. ${ }^{30,31}$ Briefly, rats were anesthetized with a $0.1-0.2 \mathrm{ml}$ of a mixture of $100 \mathrm{mg} / \mathrm{ml}$ ketamine and $20 \mathrm{mg} / \mathrm{ml}$ xylazine. Pupils were dilated with a topical application of $5.0 \%$ phenylephrine and $0.8 \%$ tropicamide. CNV was experimentally produced with an argon dye-pulsed laser (Novus Varia, Lumenis, Salt Lake City, UT) and a slit lamp delivery system (SL-130; Carl Zeiss Meditec GmbH, Oberkochen, Germany) at a spot size of $100 \mu \mathrm{m}$, duration of $0.05 \mathrm{~s}$, and intensity of $200 \mathrm{~mW}$. Four laser photocoagulations were applied to each eye between the major retinal vessels around the optic disk under the previously described conditions. ${ }^{30}$ The morphological end point of the laser injury was the appearance of a cavitation bubble, a sign that is thought to correlate with the disruption of Bruch's membrane. On occasion, the inducing laser burst created an extensive subretinal hemorrhage, and these spots were excluded from any further treatment or analysis.

\section{Evaluation of Effects of Topical Bromfenac on Experimental CNV}

A total of 20 male Brown-Norway rats were divided into saline-treated group and bromfenac-treated group. All rats underwent laser photocoagulation of the right eye as described above. Saline-treated group rats received eye drops of saline six times a day for 7 days. Drug administration was started the day after photocoagulation (day 1), and continued until day 7. Bromfenac-treated rats were received eye drops of human use bromfenac ophthalmic solution (Bronuk 0.1\% ophthalmic solution, Senju Pharmaceutical) six times a day, for 7 days. The eyes were enucleated on day 8 and subjected to further examinations.

\section{Choroidal Flat Mounts}

Rats were anesthetized and perfused with $1 \mathrm{ml}$ PBS containing $50 \mathrm{mg} / \mathrm{ml}$ fluorescein-labeled dextran (Sigma Aldrich, St Louis, MO) as previously described elsewhere. ${ }^{12,13}$ After the eyes were enucleated and briefly fixed in 4\% PFA, the anterior segment was removed and the retina was carefully dissected from the eyecup. Four to six radial cuts were made from the edge to the equator, and the eyecup was flat mounted with the sclera facing down and viewed with a Zeiss fluorescence microscope. Images were captured using the same exposure time for each comparative section, taken with a CCD camera, and the sizes of CNV lesions were measured using Image J.

\section{Western Blot Analysis}

Retina-choroid whole mounts were isolated and frozen at $-80^{\circ} \mathrm{C}$ within $2 \mathrm{~min}$ after enucleation. Retina-choroids were later ultrasonically homogenized and cytoplasmic protein extracts were isolated using a Pierce NE-PER nuclear and cytoplasmic extraction kit (Pierce) at $4{ }^{\circ} \mathrm{C}$. The protein extracts $(20 \mu \mathrm{g}$ of protein in each lane) were subjected to the western blot analysis described above. For quantification, blots of five independent experiments were used.

\section{Immunofluorescent Staining}

Indirect immunofluorescent staining was carried out as described previously. ${ }^{28,29}$ Enucleated eyes from the rats were immediately fixed in $4 \%$ paraformaldehyde at $4{ }^{\circ} \mathrm{C}$ for $12 \mathrm{~h}$. The anterior segment and the lens were removed, and the remaining eyecup was cytoprotected with $10-30 \%$ sucrose in PBS. The eyecups were then frozen in an optimal cutting temperature compound (Sakura Finetech, Tokyo, Japan). Frozen sections $(7 \mu \mathrm{m})$ were dried and blocked with blocking buffer for $1 \mathrm{~h}$. The antibodies used for staining were rabbit polyclonal anti-Nrf2 antibody, rabbit polyclonal anti-HO-1 antibody (each 1:100; Santa Cruz Biotechnology Inc.), mouse anti-CD68 monoclonal antibody (ED1; 1:800; Serotec, Raleigh, NC), mouse anti-glial fibrillary acidic protein (GFAP) monoclonal antibody (1:400; Sigma Aldrich), mouse anti-RPE 65 monoclonal antibody, and mouse anti-CD31 monoclonal antibody (PECAM-1; 1:250 and 1:100, respectively; Abcam, Cambridge, UK). Normal rabbit or mouse IgG was used instead of primary antibody as a negative control in each case. Secondary antibodies were Alexa-Fluor 488-conjugated goat anti-mouse $\operatorname{IgG} \mathrm{F}(\mathrm{ab}) 2$ fragment and Alexa-Fluor 594-conjugated goat anti-rabbit IgG F(ab)2 fragment (each 1:400; Molecular Probes). Slides were 
counterstained with DAPI, mounted with Shandon PermaFluor (Thermo Scientific), and viewed with a Zeiss fluorescence microscope. Images were captured using the same exposure time for each comparative section. For all experiments, at least three sections from each eye were evaluated. To quantify the macrophage infiltration, 10 different images were randomly selected by a controller (NY) and examined by masked observers (NA and $\mathrm{HO}$ ).

\section{Evaluation of Intraocular VEGF}

We also measured concentrations of VEGF in the intraocular fluid (mixture of aqueous humor and vitreous fluid) as described previously with some modifications. ${ }^{30}$ On day 8 , the eyes were enucleated under deep anesthesia, the conjunctival tissue was removed, and the remaining eye tissues (cornea, iris, vitreous body, retina, choroids, and sclera) were collected in a tube and four to six radial cuts were made from the equator to cornea edge and to optic nerve at $4{ }^{\circ} \mathrm{C}$. After centrifugation at $12000 \mathrm{~g}$ for $30 \mathrm{~s}$, supernatants were collected, and the concentrations of VEGF were measured using ELISA development kits (R\&D Systems, Minneapolis, $\mathrm{MN})$. VEGF concentration was adjusted by each protein concentration as previously described. ${ }^{29}$ The adjusted concentration from a single eye was used as the concentration of VEGF.

\section{Statistical Analysis}

Because of the skewed distribution, the results were analyzed statistically using nonparametric tests (Mann-Whitney $U$-test) and were expressed as mean and range.
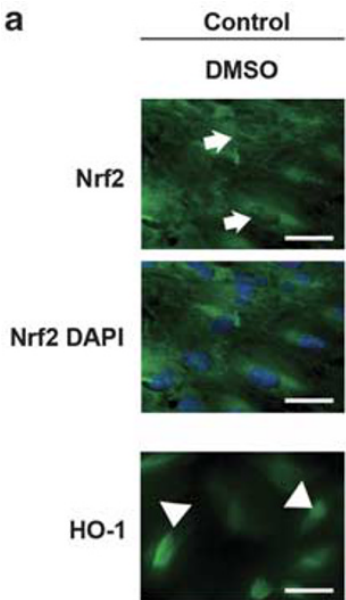

HO-1 DAPI

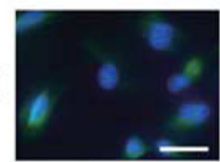

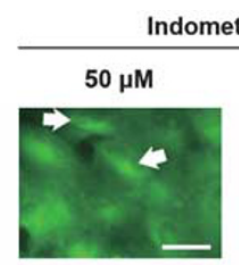
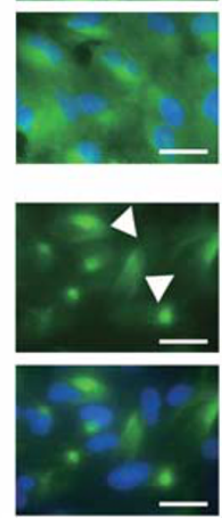

Statistical analyses were performed using SPSS software version 16.0 (SPSS Inc., Chicago, IL). A P-value of 0.05 was considered to be statistically significant. To adjust for inflated error resulting from multiple comparisons, the corrected significant $P$-value was defined as $0.05 / 4$ using the Bonferroni correction for multiple comparisons.

\section{RESULTS \\ NSAIDs Translocated Nrf2 and Upregulated HO-1 in Cultured RPE Cells}

First, we examined whether transcriptional factor Nrf2 and phase 2 anti-oxidative protein $\mathrm{HO}-1$ were expressed in ARPE-19 cells. Immunocytochemistry showed Nrf2 was located mainly in the cytoplasm and that HO-1 expression was barely detected in an untreated condition. After treatment with indomethacine or bromfenac, Nrf2 was translocated into the nucleus and HO-1 was abundantly present in the perinuclear lesion and cytoplasm (Figure 1).

Western blot analysis showed that treatment with indomethacine resulted in maximal immunoreactivity against $\mathrm{Nrf} 2$ at a concentration of $250 \mu \mathrm{M}$ and $24 \mathrm{~h}$ of treatment, whereas HO-1 showed maximal band at a concentration of $50 \mu \mathrm{M}$, and this remained constant at 50-250 $\mu \mathrm{M}$ and showed maximal at $12 \mathrm{~h}$ of treatment. Treatment with bromfenac also showed maximal immunoreactivity for Nrf2 at a concentration of $160 \mu \mathrm{M}$. HO-1 showed maximal band at $40 \mu \mathrm{M}$ and remained at $80 \mu \mathrm{M}$. Time-course examination showed maximal immunoreactivity at $12 \mathrm{~h}$ (Figure 2).

b
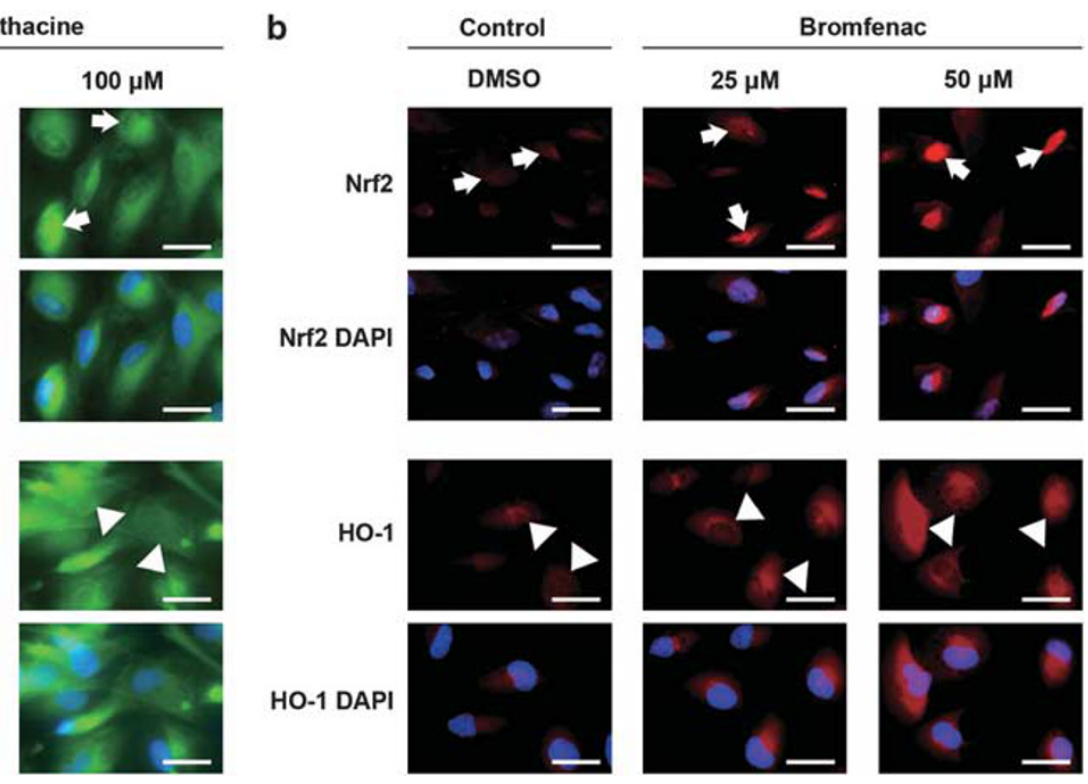

Figure 1 Expressions of Nrf2 and HO-1 protein in immunocytochemistry of ARPE-19 cells. (a) Treatment with the indicated concentration of indomethacine

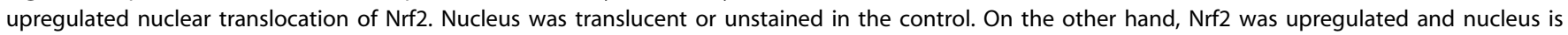
stained after indomethacine treatment (arrows). Cellular expressions of HO-1 were also upregulated in cytosol and nucleus (arrowheads). Scale bars: $30 \mu \mathrm{m}$. (b) Treatment with bromfenac also showed activation and increased Nrf2 expression in nucleus (arrows). Treatment with bromfenac increased the expression of HO-1 in nucleus and cytosol, especially around nucleus (arrowheads). Scale bars: $30 \mu \mathrm{m}$. 


\section{Bromfenac Inhibited RPE Cell Apoptosis Caused by Oxidative Stress}

It has been reported that $\mathrm{HO}-1$ has an anti-apoptotic property in human gastric mucosal cells. ${ }^{32}$ We examined whether HO-1 induced by NSAIDs has functional properties against oxidative stress in ARPE-19 cells. $\mathrm{H}_{2} \mathrm{O}_{2}$ increased cell apoptosis in either DMSO-treated or bromfenac-treated cells $(15.6 \pm 4.01 \%$ to $26.2 \pm 4.22 \%$ in DMSO-treated control cells; $P<0.001$ vs $15.3 \pm 2.91 \%$ to $20.3 \pm 3.02 \%$ in bromfenactreated cells; $P<0.005)$. Apoptosis induced by oxidative stress was significantly less in bromfenac-treated cells compared with DMSO-treated control cells $(20.3 \pm 3.02 \%$ bromfenactreated cells vs $26.1 \pm 4.22 \%$ DMSO-treated cells; $P<0.01$ ). Treatment with bromfenac itself resulted in no significant difference in apoptosis $(15.6 \pm 4.01 \%$ DMSO-treated cells vs $15.3 \pm 2.91 \%$ bromfenac-treated cells; $P=0.86$; Figure 3a and $b$ ).

We also tested cell viability in ARPE-19 cells using MTT assay. As described using propidium iodide staining and a FACS analyzer, $\mathrm{H}_{2} \mathrm{O}_{2}$ increased cell death of either DMSO-treated or bromfenac-treated cells $(0 \%$ to $29.0 \pm 2.89 \%$ in DMSO-treated control cells; $P<0.001 \mathrm{vs}$ $0.702 \pm 5.73 \%$ to $23.5 \pm 4.04 \%$ in bromfenac-treated cells; $P<0.001)$. Cell death induced by oxidative stress was significantly less in bromfenac-treated cells compared with DMSO-treated control cells $(23.5 \pm 4.04 \%$ bromfenac-treated cells vs $29.0 \pm 2.89 \%$ DMSO-treated cells; $P<0.001$ ). Treatment with bromfenac itself made no significant difference to cell viability reduction (0\% DMSO-treated cells vs $\quad 0.702 \pm 5.73 \%$ bromfenac-treated cells; $P=0.519$; a

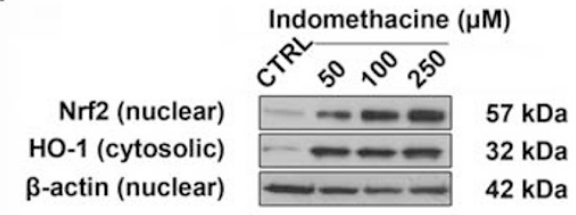

Nrf2 (nuclear) HO-1 (cytosolic) $\beta$-actin (nuclear)
Indomethacine $(\mathrm{h})$

$\begin{array}{lllll}0 & 3 & 6 & 12 & 24\end{array}$

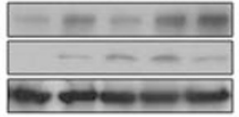

$57 \mathrm{kDa}$

$32 \mathrm{kDa}$

$42 \mathrm{kDa}$

b

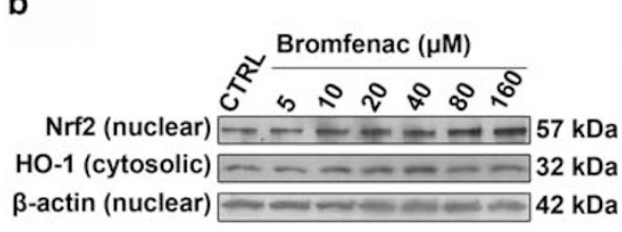
$\mathrm{HO}-1$ (cytosolic) $32 \mathrm{kDa}$ race

Nrf2 (nuclear)
HO-1 (cytosolic)
$\beta$-actin (nuclear)

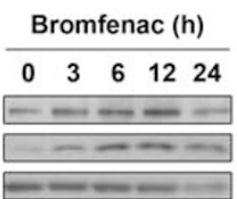

$57 \mathrm{kDa}$

$32 \mathrm{kDa}$

$42 \mathrm{kDa}$
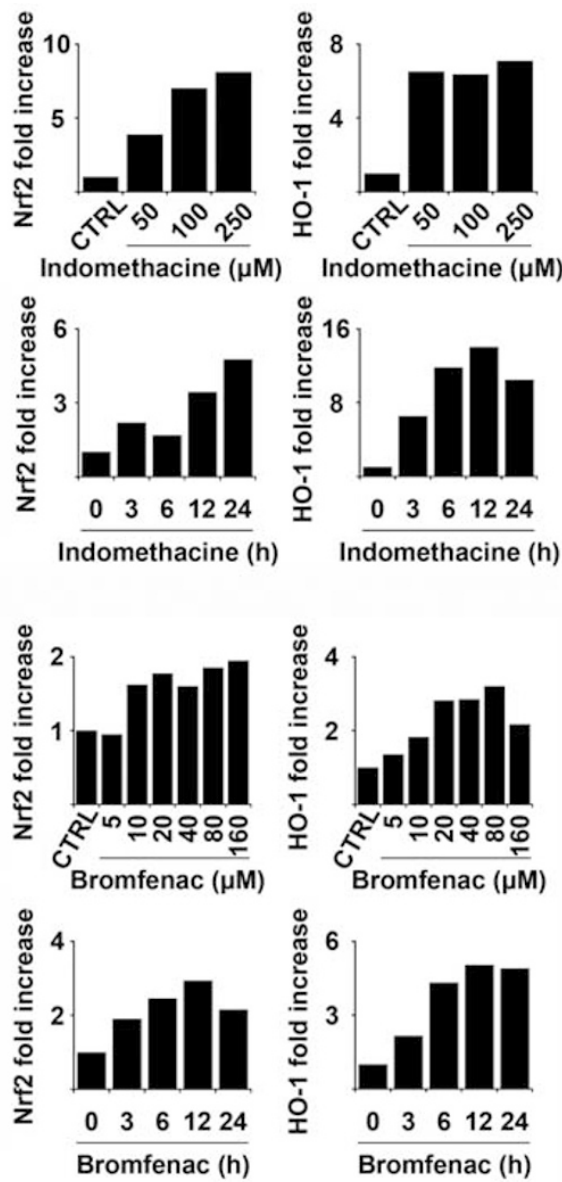

Figure 2 Nrf2 or HO-1 expression in ARPE19 cells by western blot analysis. (a; Top row) Serum-starved ARPE-19 cells were stimulated with indomethacine for $3 \mathrm{~h}$ and Nrf2 in nuclear protein and HO-1 in cytosolic protein were analyzed using western blots. Nrf2 in nuclear protein was increased by indomethacine in a dose-dependent manner. HO- 1 in cytosolic protein is upregulated markedly with $50 \mu \mathrm{M}$ indomethacine and this trend was continued through stimulation with $250 \mu \mathrm{M}$. (Bottom row) ARPE-19 cells were stimulated with indomethacine ( $250 \mu \mathrm{M}$ ) for the indicated time and subjected to the same analysis. Nrf2 in nuclear protein showed a time-dependent increase. On the other hand, HO- 1 in cytosolic protein was showed maximal immunoreactivity at $12 \mathrm{~h}$. (b; Top row) ARPE-19 cells were also stimulated with bromfenac for $3 \mathrm{~h}$. Nrf2 was also upregulated in a dose-dependent manner. Increase of HO-1 in cytosolic protein was nearly the same as Nrf2 in nuclear protein. (Bottom row) Time-course expression of Nrf2 in nuclear protein and $\mathrm{HO}-1$ in cytosolic protein with bromfenac (100 $\mu \mathrm{M})$. 
Figure 3c). Statistics were subjected to Mann-Whitney $U$-test with Bonferroni correction.

\section{Reduction of Experimental CNV Size by Bromfenac in Rat Model}

Our in vitro experiments showed that NSAIDs attenuated $\mathrm{H}_{2} \mathrm{O}_{2}$-induced RPE cell apoptosis. Next we examined the effects of bromfenac ophthalmic solution in a rat model of
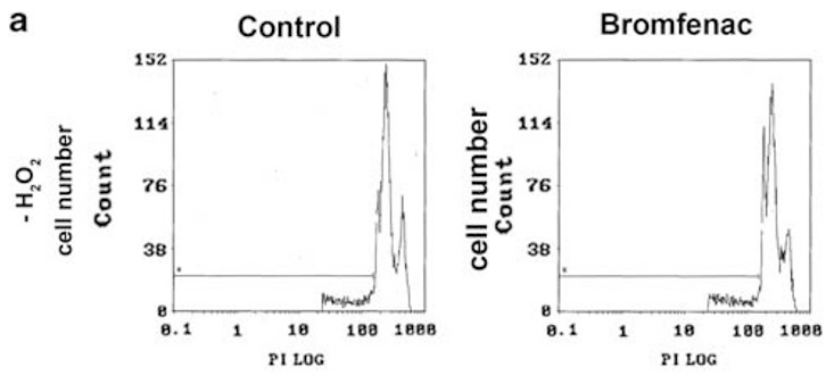

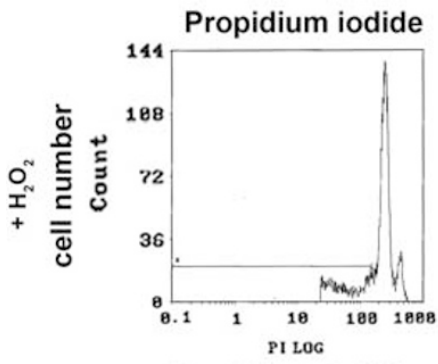

Propidium iodide

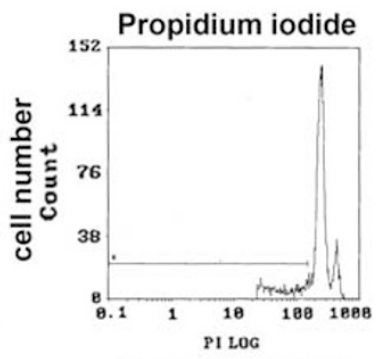

Propidium iodide b
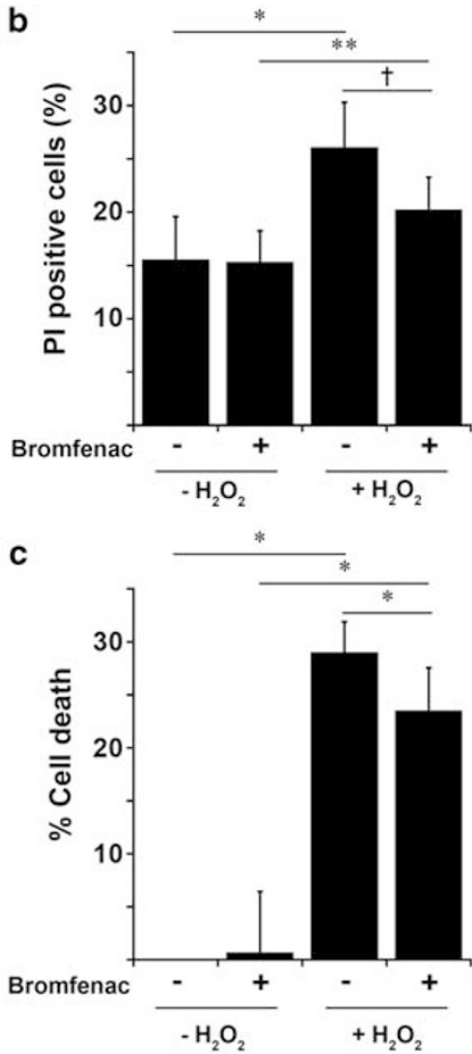

CNV. The size of CNV was measured with flat-mounted choroid stained with fluorescein dextran (Figure 4a). As shown in Figure $4 \mathrm{~b}, \mathrm{CNV}$ size was significantly smaller in bromfenac-treated eye $\left(32176 \pm 9165.1 \mu \mathrm{m}^{2}\right)$ than in salinetreated rats $\left(48383 \pm 12733 \mu \mathrm{m}^{2} ; P<0.001\right.$, Mann-Whitney $U$-test).

\section{Bromfenac Upregulated Nrf2 and HO-1 in Experimental CNV}

The size of experimental CNV was reduced by topical bromfenac. To examine the underlying mechanism, we evaluated expressions of Nrf2 and HO-1 in the CNV area. Our results in vitro showed Nrf2 was strongly stained in cell nucleus especially at and adjacent to the $\mathrm{CNV}$ area in rats that received bromfenac compared with the control rats. At the same time, expression of HO- 1 was observed in cells at CNV lesions. Notably, HO-1 was also strongly found not only at the CNV area but also in the entire retina (Figure $5 a$ and $b$ ). To identify the cell type to express HO-1 in bromfenactreated eyes, the eyes were double stained using anti HO-1 antibody and antibodies specific to each cell type. AntiRPE65 antibody for RPE cells, anti-GFAP antibody for glial cells, anti-ED1 antibody for macrophages, and anti-CD31 antibody for endothelial cells in the rat CNV model were treated with bromfenac. HO-1 were obviously co-stained with RPE65, GFAP, ED1 antibodies (arrows), implying that RPE cells, GFAP-positive cells (astrocytes or Müller cells), and ED1-positive macrophages were strongly correlated with $\mathrm{HO}-1$ production. $\mathrm{HO}-1$ was also upregulated around

Figure 3 Anti-apoptotic effect of bromfenac was analyzed by flow cytometry. (a) ARPE-19 cells were pretreated with bromfenac (left lane) or DMSO (right lane) as a control for $24 \mathrm{~h}$. Then, the cells were stimulated with (bottom) or without (top) $1 \mathrm{mM} \mathrm{H}_{2} \mathrm{O}_{2}$ for $3 \mathrm{~h}$. After stimulation, the cells were stained with $\mathrm{Pl}$, and the DNA content was determined with a FACS analyzer. (b) $\mathrm{H}_{2} \mathrm{O}_{2}$ increased cell apoptosis in both DMSO-treated and bromfenac-treated cells ( ${ }^{*} P<0.001$ and ${ }^{*} P<0.005$, respectively). Apoptosis induced by oxidative stress was significantly less in bromfenac-treated cells compared with DMSO-treated control cells $\left({ }^{\dagger} P<0.01\right)$. Treatment with bromfenac itself resulted in no significant difference in apoptosis $(P=0.86)$. Each group included results of 10 independent examinations $(n=10)$. Data were expressed as mean \pm s.e.m. The corrected significant $P$-value (Mann-Whitney $U$-test) was defined as 0.0125 (0.05/4 comparisons) after Bonferroni correction. (c) Cytoprotective effect of bromfenac was analyzed using MTT assay. ARPE-19 cells were pretreated with bromfenac or DMSO as control for $24 \mathrm{~h}$. Then cells were stimulated with or without $500 \mu \mathrm{M} \mathrm{H}_{2} \mathrm{O}_{2}$ for $15 \mathrm{~min}$. After stimulation, cells were incubated with $\mathrm{MTT}(0.5 \mathrm{mg} / \mathrm{ml})$ for $3 \mathrm{~h}$, formazan product was solubilized by DMSO, dehydrogenase activity was expressed as absorbance and \% cell death was determined compared with control. $\mathrm{H}_{2} \mathrm{O}_{2}$ increased cell death in both DMSO-treated and bromfenac-treated cells $\left({ }^{*} P<0.001\right)$. Cell death induced by oxidative stress was significantly less in bromfenactreated cells compared with DMSO-treated control cells $\left({ }^{*} P<0.001\right)$. Treatment with bromfenac itself made no significant difference in cell viability $(P=0.519)$. $(n=16)$. Data were expressed as mean \pm s.e.m. The corrected significant $P$-value (Mann-Whitney $U$-test) was defined as 0.0125 (0.05/4 comparisons) after Bonferroni correction. 

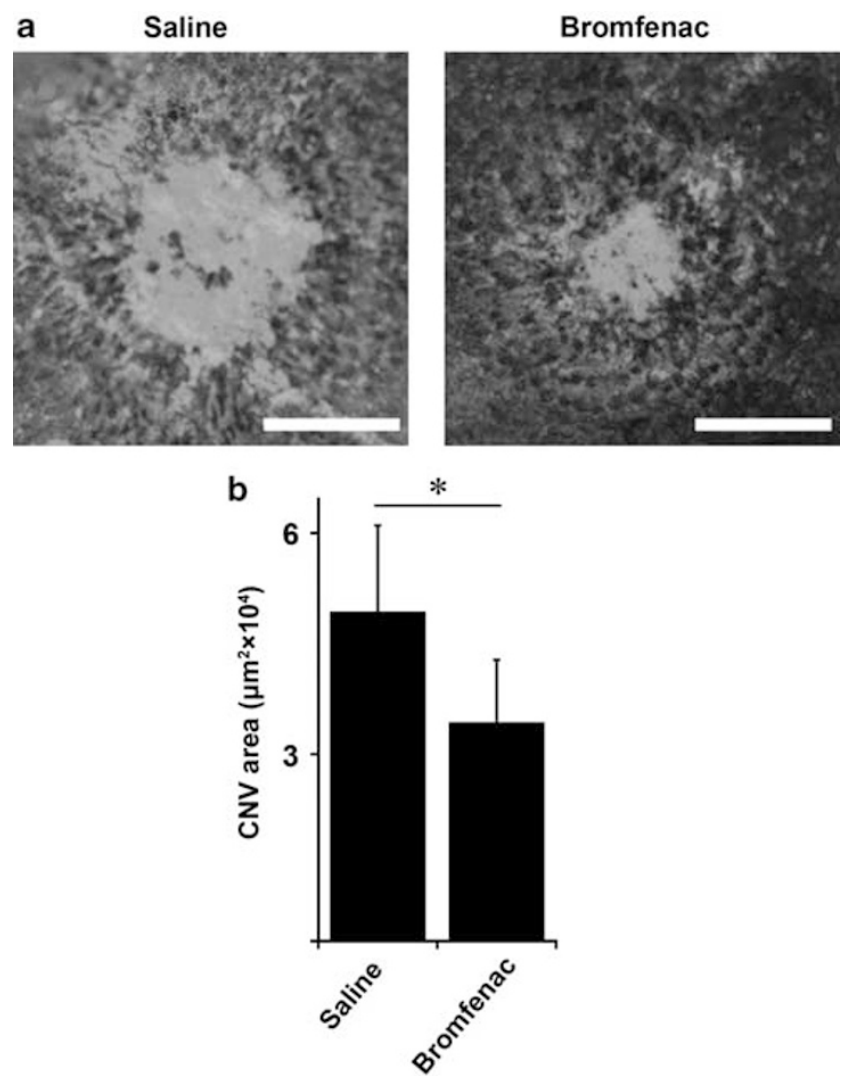

Figure 4 Size of CNV was examined after bromfenac treatment. (a) Representative CNV lesions of CNV flat mounts. Scale bars: $200 \mu \mathrm{m}$. (b) An analysis of the sizes of CNV lesions 8 days after PC. CNV size is smaller in bromfenac eye drop-treated rats $32176 \pm 9165.1 \mu \mathrm{m}^{2}$ than saline eye-drop treated rats $48383 \pm 12733 \mu \mathrm{m}^{2}\left({ }^{*} P<0.001\right.$, Mann-Whitney $U$-test). $n=40$ (40 PC spots of 10 rats). Data were expressed as mean \pm s.e.m.

CD31-positive blood vessels, but less co-staining was observed compared with RPE cells or GFAP-positive cells (arrowheads; Figure 5c).

We also examined the protein quantity of $\mathrm{Nrf} 2$ and $\mathrm{HO}-1$ using homogenates of retina and choroid of rat CNV model. Western blot analysis showed no immunoreactivity to Nrf2. It is more than probable that the concentration of Nrf2 in the prepared nuclear extract was too low to be detected. Western blot analysis of cytosolic extracts showed that HO-1 was upregulated in the tissue of rat treated with bromfenac as observed in immunohistochemical analysis (Figure 6a). An analysis using densitometry of five independent western blot results confirmed upregulation of HO-1 in bromfenac-treated eyes and photocoagulated (PC) eyes (Figure 6b). Expressions of HO-1 in saline-treated eyes with no PC were defined as base line, and fold increases of HO-1 in other eyes were calculated. Topical bromfenac significantly upregulated HO-1 expression ( $1.85 \pm 0.19$-fold, $P<0.01$ ), and bromfenac-treated eyes with $\mathrm{PC}$ expressed more significant $\mathrm{HO}-1$ expression $(2.21 \pm 0.36$-fold, $P<0.01)$ compared with salinetreated eyes. Although there was no statistical significance,
PC itself slightly upregulated HO-1 expression by $1.21 \pm 0.24$-fold).

\section{HO-1 Inhibitor Stannic Mesoporphyrin (SnMP) Reversed Inhibitory Effect of Bromfenac on CNV}

Upregulation of HO-1 by NSAIDs was observed both in our in vitro and in vivo experiments. We examined whether the inhibition of HO-1 changed the size of experimental CNV. Topical bromfenac decreased the size of CNV compared with the control (bromfenac rat $28191 \pm 5466 \mu \mathrm{m}^{2}$ vs control rat $42405 \pm 9004 \mu \mathrm{m}^{2}$ control: $\left.P<0.001\right)$. This inhibitory effect was diminished by intraperitoneal injection of SnMP (iSnMP; bromfenac rat $28191 \pm 5466 \mu \mathrm{m}^{2}$ vs bromfenac + iSnMP rats $44677 \pm 7619 \mu \mathrm{m}^{2}, P<0.001$ or control rat $42405 \pm 9004 \mu \mathrm{m}^{2}$ vs bromfenac + iSnMP rats $\left.44677 \pm 7619 \mu \mathrm{m}^{2}, P=0.923\right)$. On the other hand, iSnMP itself did not have any significant effect on CNV size (44057 $\pm 14775 \mu \mathrm{m}^{2}$; Figure 7).

\section{Inhibitory Effect of Bromfenac on Macrophage Infiltration Was Diminished by SnMP}

The above experiments revealed that topical bromfenac reduced the size of the CNV, and iSnMP reversed this reduction (Figure 8). To identify the mechanisms underlying this phenomenon, we measured the number of macrophages infiltrating into the CNV area. As a result, in the group which received intraperitoneal PBS (iPBS), infiltration of macrophage was significantly decreased in bromfenac-treated eyes compared with saline-treated eyes $(18.0 \pm 6.04$ cells/field bromfenac $+\mathrm{iPBS}$ rats $v s 32.4 \pm 6.07$ cells/field saline $+\mathrm{iPBS}$ rats; $P<0.01)$. iSnMP reversed this effect and significantly increased macrophage infiltration (18.0 \pm 6.04 cells/field bromfenac $+\mathrm{iPBS}$ rats vs $37.4 \pm 4.28$ cells/field bromfenac + iSnMP rats; $P<0.01)$. There was no significant change with macrophage infiltration in saline-treated rats $(31.0 \pm 4.24$ cells/field saline $+\mathrm{iSnMP}$ rats $v s, 37.4 \pm 4.28$ cells/field bromfenac + iSnMP rats; $P=0.074)$.

\section{Reduction of Intraocular VEGF by Bromfenac Was Diminished by SnMP}

The amount of VEGF in ocular fluid obtained from the CNV model on day 8 was evaluated with ELISA. As a result, the amount of VEGF increased in CNV model in comparison with rat eyes without laser burn. VEGF level was significantly lower in bromfenac-treated rat than control CNV rats $(1.09 \pm 0.88 \mathrm{pg} / \mathrm{mg}$ protein bromfena $+\mathrm{iPBS}$ rats $v s$ $3.08 \pm 3.19 \mathrm{pg} / \mathrm{mg}$ protein saline $+\mathrm{iPBS}$ rats; $P<0.01)$. Additional iSnMP increased intraocular VEGF level as high as that of control $\mathrm{CNV}$ rats $(5.35 \pm 4.23 \mathrm{pg} / \mathrm{mg}$ protein bromfenac + iSnMP rats $v s 1.09 \pm 0.88 \mathrm{pg} / \mathrm{mg}$ protein bromfenac $+\mathrm{iPBS}$ rats; $P<0.001)$. No significant difference resulted from iSnMP itself $(4.09 \pm 3.87 \mathrm{pg} / \mathrm{mg}$ protein saline $+\mathrm{iSnMP}$ rats vs $3.08 \pm 3.19 \mathrm{pg} / \mathrm{mg}$ protein saline $+\mathrm{iPBS}$ rats; $P=0.499$; Figure 9). 
a

Nrf2 DAPI
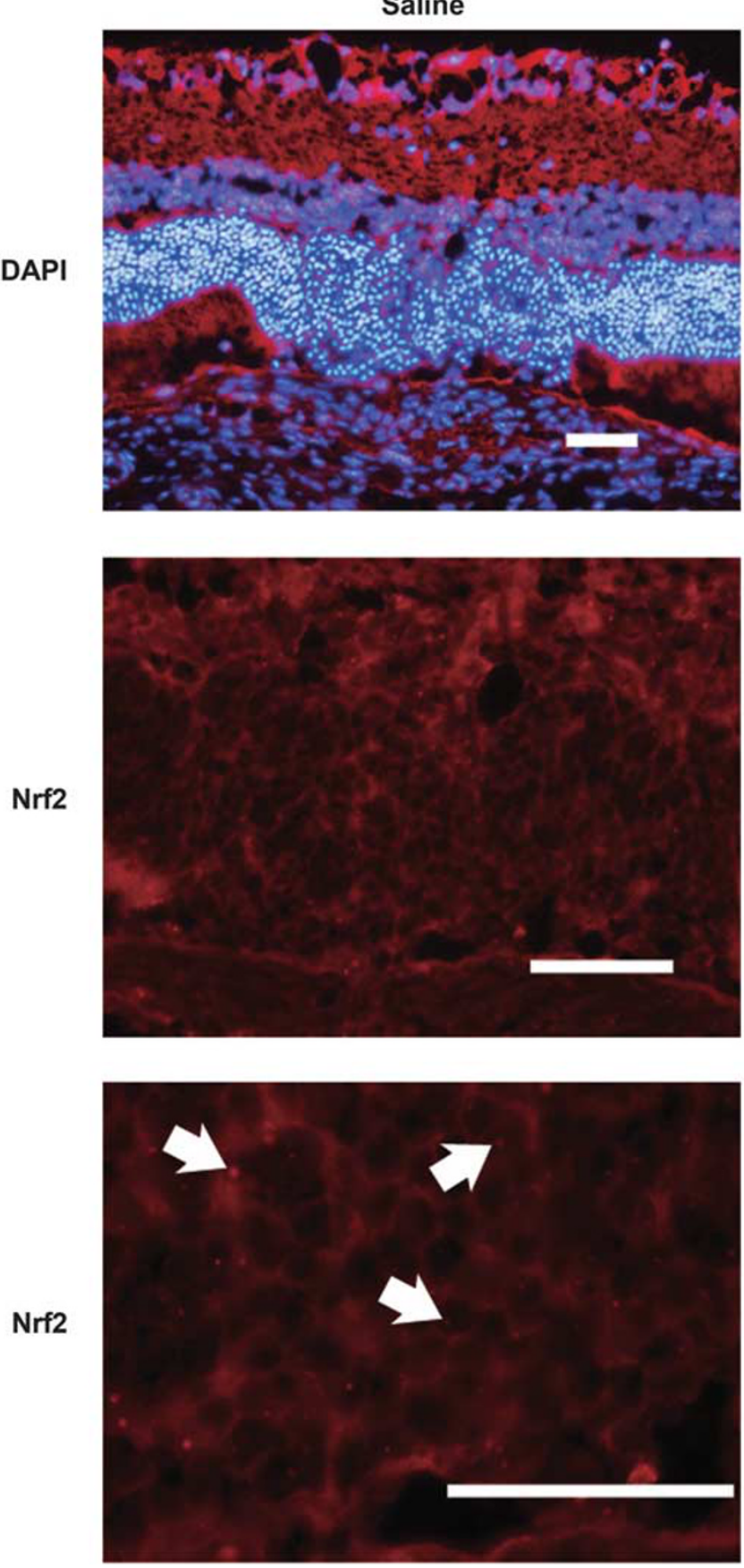
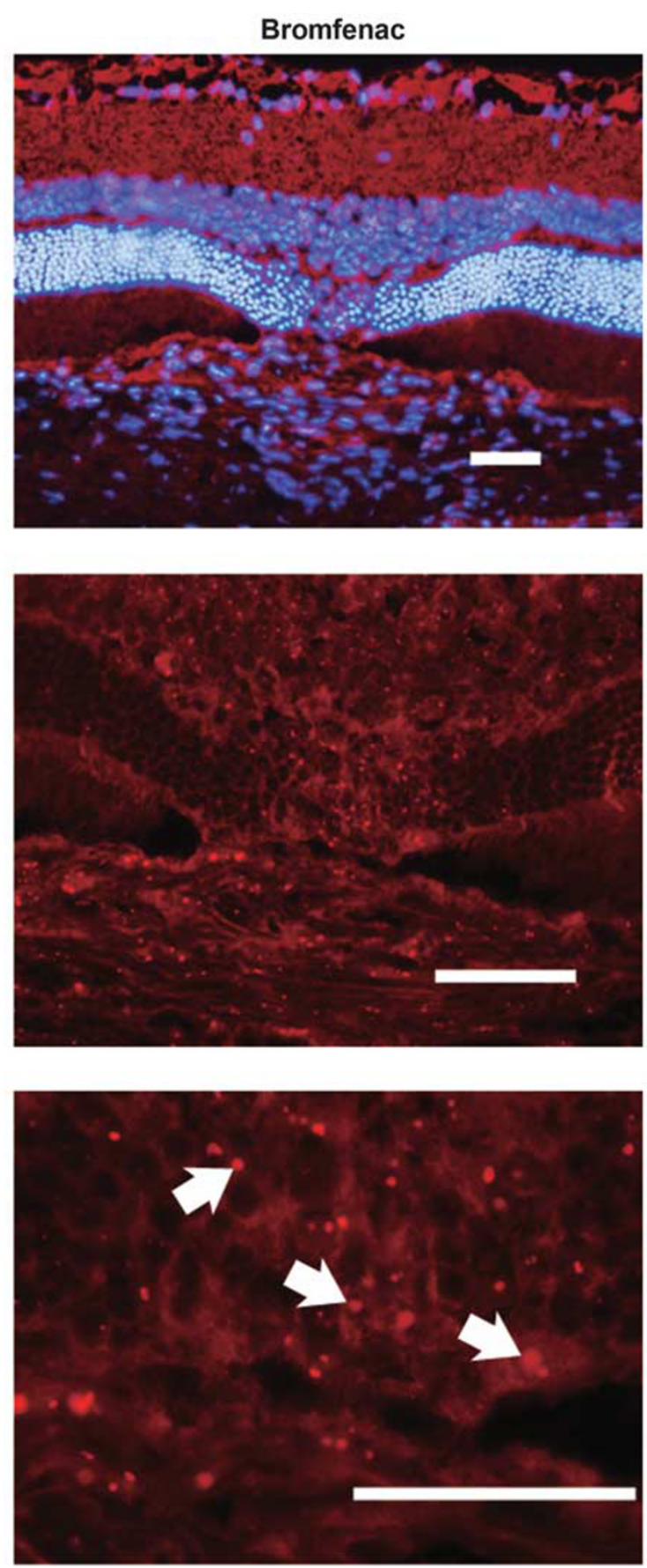

Figure 5 Immunohistochemical analysis was carried out for CNV lesions using Nrf2 or HO-1 protein. Immunofluorescent study was performed with anti-Nrf2 antibody (a) and anti-HO-1 antibody (b) in rat CNV model. Nuclei were counter-stained with 4'-6-diamidino-2-phenylindole (DAPI). (a) The results showed that expression of Nrf2 was upregulated and accumulated in cell nuclear especially at and near the CNV lesion (arrows). (b) Expression of HO-1 was also upregulated with bromfenac eye drop compared with saline-treated eye, especially at the photocoagulated CNV area and inner limited membrane (arrowheads). Scale bars: $100 \mu \mathrm{m}$. (c) Double staining for immunohistochemical analysis with anti-HO-1 antibody and cell-specific antibodies. Anti-RPE65 antibody for RPE cells, anti-GFAP antibody for glial cells, anti-ED1 antibody for macrophages, and anti-CD31 antibody for endothelial cells were in rat CNV model treated with bromfenac. HO-1 were obviously co-stained with RPE65, GFAP, ED1 antibodies (arrows), implying that RPE cells, GFAP-positive cells (astorcytes or Müller cells) and ED1-positive macrophages were strongly correlate with HO-1 production. HO-1 was also upregulated around CD31-positive blood vessels but less co-staining was observed compared with RPE cells or GFAP-positive cells (arrowheads). Nuclei were counter stained with DAPI. Scale bars: $100 \mu \mathrm{m}$. 
b

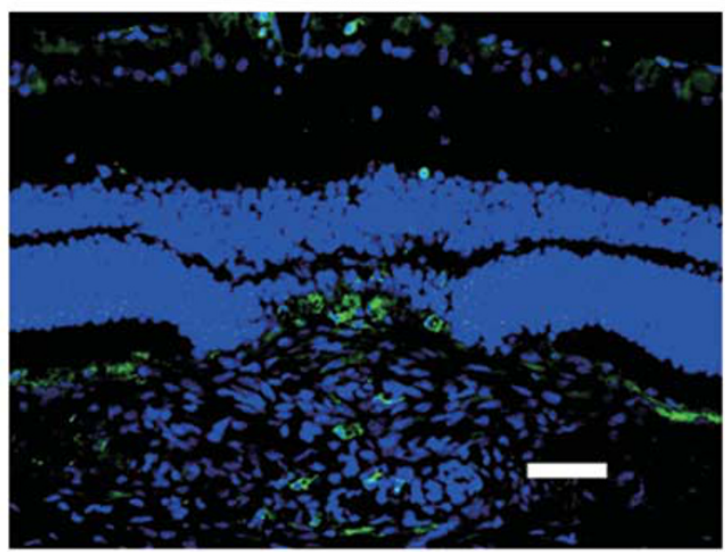

HO-1

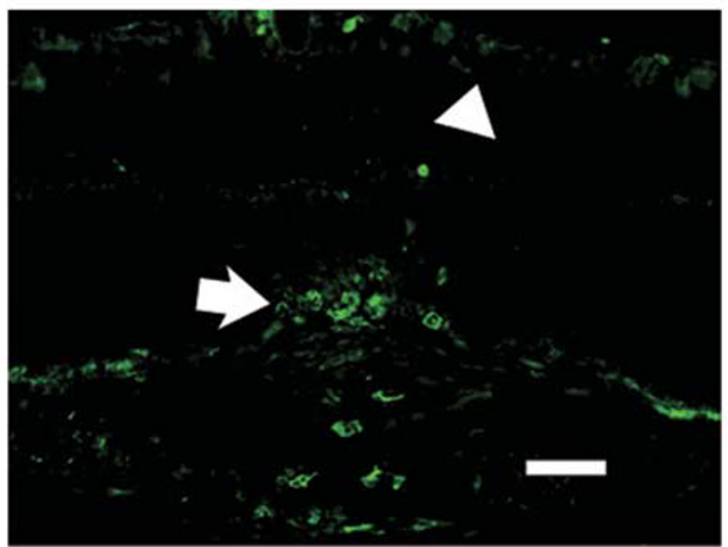

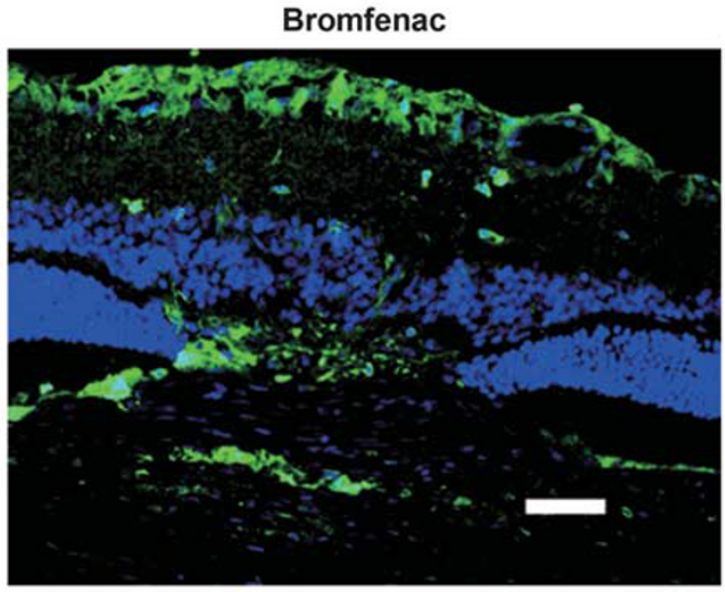

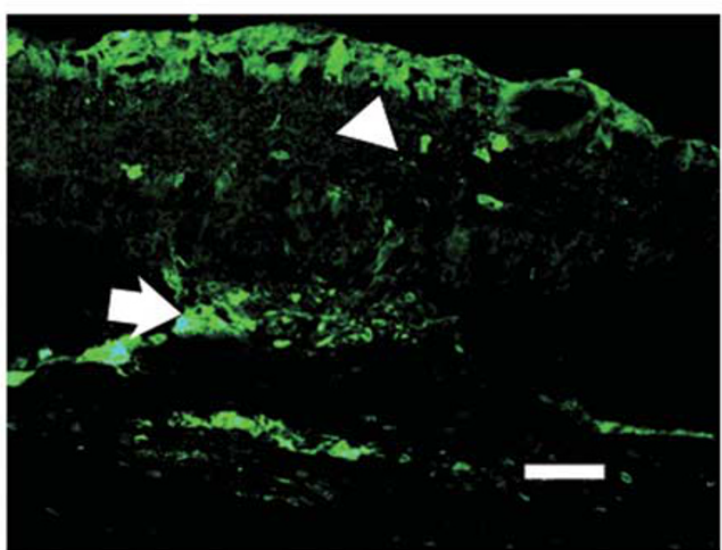

Figure 5 Continued.

\section{DISCUSSION}

Previously, we reported that intravitreous NSAIDs inhibited laser-induced $\mathrm{CNV}$ in sub-human primate; however, its mechanism was not well addressed. ${ }^{11}$ Several recent reports showed possible mechanisms of the inhibitory effect of NSAIDs on CNV ${ }^{11-18}$ VEGF is one of the most potent molecules in angiogenesis. Takahashi et al ${ }^{13}$ reported that nepafenac inhibited neovascularization in mice with $\mathrm{CNV}$ due to laser-induced rupture of Bruch's membrane and Kim et al $^{16}$ showed that ketrolac reduced the size of laser-induced CNV. Both suggested that the inhibitory effect of NSAIDs was due to downregulation of VEGF expression in the retina. Our previous study showed that blocking VEGF by gene transfer strongly inhibited $\mathrm{CNV}$ in this model. ${ }^{31}$ Indeed, intraocular VEGF was significantly reduced in bromfenactreated eyes in this study and thus inhibition of VEGF was also likely to have a crucial role in the inhibition of $\mathrm{CNV}$ formation found in this study.

There may be several explanations for the mechanism of this phenomenon. The first is the direct effect of NSAIDs on endothelial cells. It was reported that NSAIDs directly affect endothelial cells to down-regulate VEGF in vitro. ${ }^{33,34}$ The targeted portions were supposed to be MAP kinase, ERK2 or the expression of VHL tumor suppressor protein, resulting in ubiquitination and degradation of HIF- $1 \alpha^{33,34}$ Another report showed that NF- $\mathrm{BB}$, which can also increase the expression of VEGF, and was inhibited by NSAIDs. ${ }^{35}$ These direct mechanisms were probably at work in the present model, at least in part. The second is that the present phenomenon was caused by the inhibition of inflammation, which is an indirect effect. This explanation would be quite understandable because inflammatory cells are major sources of VEGF and depletion of macrophage strongly reduced the size of $\mathrm{CNV}$, as demonstrated by ourselves and others. ${ }^{36}$ NSAIDs were reported to reduce the prostaglandin, which is a known potent inducer of inflammation, in mouse retina. ${ }^{14,16}$ Besides, NF- $\kappa B$ has a central role in the expression of various pro-inflammatory mediators and leukocyte infiltration. ${ }^{37}$ So inflammation was inhibited by NSAIDs, consequently reducing the size of CNV. This is compatible with the present result that the number of macrophages infiltrating into the laser burned areas was significantly less in bromfenac-treated eyes than in PBS-treated controls.

In contrast, we shed light on another mechanism of NSAIDs in this study, ie, anti-stress protein in NSAIDsmediated CNV suppression. Nrf2 is located at the cytosol binding to Keap1 under a stress-free condition; whereas after activation under the stressors, Nrf2 translocates to the 

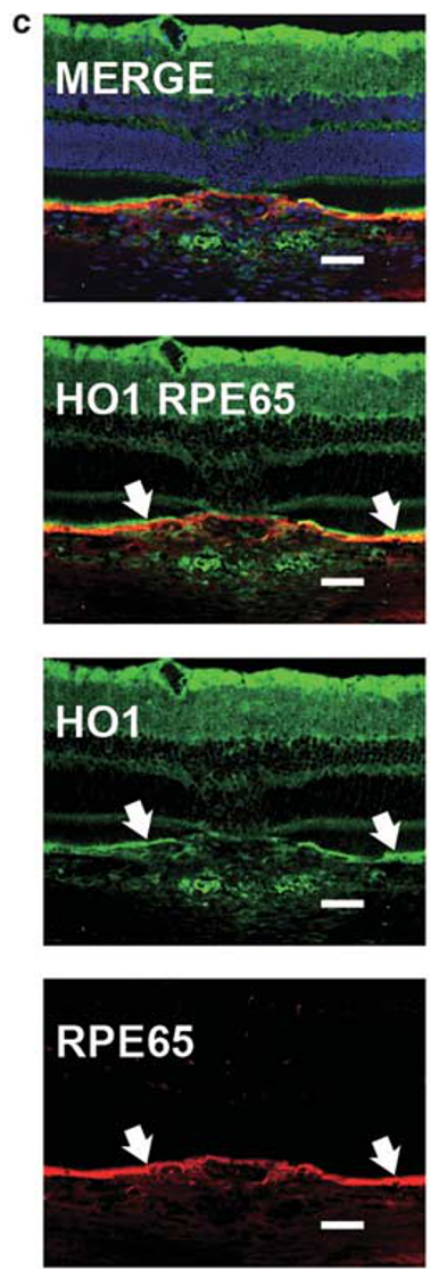

Figure 5 Continued

nucleus, where it binds to the consensus cis-element (Mafrecognition element) to turn on the anti-oxidative stress mechanism, which can result in cell protection. ${ }^{38,39}$ Because COX2 inhibits the activity of Nrf2, NSAIDs are supposed to activate the Nrf2/ARE pathways. ${ }^{39,40} \mathrm{HO}-1$ is a phase II drugdetoxifying enzyme, such enzymes are regulated in a coordinated manner through a consensus cis-element and transcription factors, such as Nrf2. The present findings in vitro are consistent with this theory.

To our knowledge, this is the first report to show that NSAIDs induce HO-1 in the retina in vivo and in vitro. Interestingly, photocoagulation itself increased HO-1 expression in the retina, suggesting that $\mathrm{HO}-1$ was induced by stress such as photocoagulation. However, HO-1 increased in bromfenac-treated eyes with no laser treatment and it was far more significant than in eyes with laser-burn alone. It is noteworthy that the inhibitory effect of bromfenac on CNV was diminished after the administration of SnMP. On the other hand, the size of CNV was not affected by saline eye drops after SnMP administration. These findings suggest that HO-1 does not necessarily have a pivotal role in CNV for-
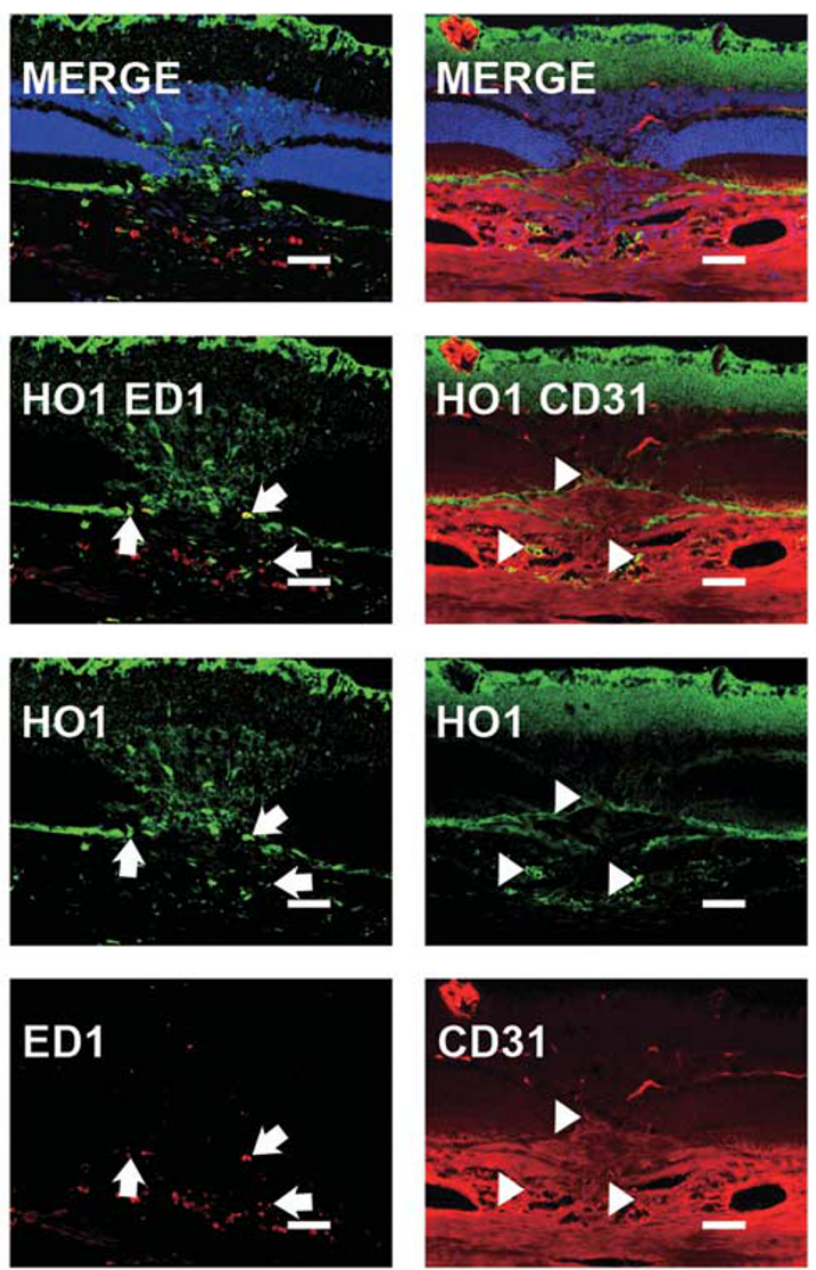

mation, but has a critical role in the inhibitory processes of bromfenac.

The role of HO-1 in angiogenesis is controversial. ${ }^{41-43}$ It is suggested that during inflammation $\mathrm{HO}-1$ has two different roles: first, an anti-inflammatory action inhibiting leukocyte infiltration; and second, promotion of VEGF-driven noninflammatory angiogenesis, which facilitates tissue repair. In this study, bromfenac increased the expression of $\mathrm{HO}-1$ associated with the inhibition of macrophage infiltration, whereas the inhibition of HO-1 by SnMP significantly augmented macrophage infiltration even in bromfenac-treated eyes. Thus, the increase of HO-1 expression by bromfenac was likely to lead to the inhibition of macrophage infiltration more than the promotion of VEGF-driven non-inflammatory angiogenesis in rat $\mathrm{CNV}$ model. Besides, our examination using intraocular fluids revealed that, bromfenac reduced the intraocular VEGF level (Figure 9). Consequently, CNV was inhibited.

Another important impact of HO-1 on retinal cells is its protective role, which was also observed as in the present in vitro study. In the in vivo study for example, curcumin 

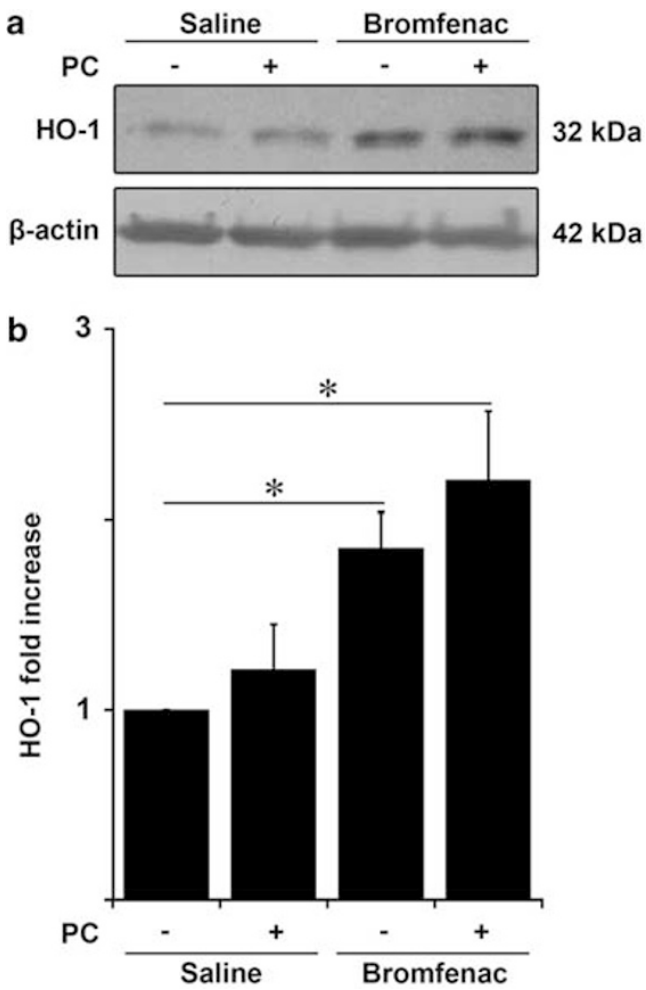

Figure 6 Western blot analysis of HO-1 in cytosolic proteins of rat retinachoroid homogenates. (a) Western blot shows HO-1 was upregulated with bromfenac and it was also slightly upregulated in eyes that received photocoagulation (PC) compared with others. (b) An analysis using densitometry on five independent western blots confirmed upregulation of HO-1 in bromfenac-treated eyes and photocoagulated eyes. Expressions of HO-1 in saline-treated eyes with no PC were defined as the base line, and fold increases of HO-1 in other eyes were calculated. Topical bromfenac significantly upregulated HO-1 expression $\left({ }^{*} P<0.01\right)$, and bromfenactreated eyes with PC expressed more significant HO-1 expression $\left({ }^{*} P<0.01\right)$ compared with saline-treated eyes. Although not statistically significant, PC itself slightly upregulated HO-1 expression. The corrected significant $P$-value (Mann-Whitney U-test) was defined as 0.0125 (0.05/4 comparisons) after Bonferroni correction. Data were expressed as mean \pm s.e.m.

protects retinal cells from light- or oxidant stress-induced cell death through the induction of $\mathrm{HO}-1 .{ }^{44}$ Overexpression of HO-1 by gene transfer also inhibited light-induced photoreceptor cell apoptosis through $\mathrm{Bcl}-2$ upregulation. ${ }^{45}$ There are other reports showing that the induction of HO-1 by various stimulants rescued the retina in an ischemia-reperfusion model. ${ }^{46}$ Therefore, NSAIDs might be beneficial for the treatment of CNV beyond their anti-angiogenic effect. This is especially true for the treatment of diseases of central nervous tissue including eye. At present, regeneration of neural tissue is clinically still difficult. Even if angiogenesis were to be blocked by an anti-VEGF drug, it would not necessarily mean the tissue function is protected. We need a potent angiogenesis therapy, but it must protect the host tissue as well. NSAIDs might be reasonable candidate drugs for this purpose.

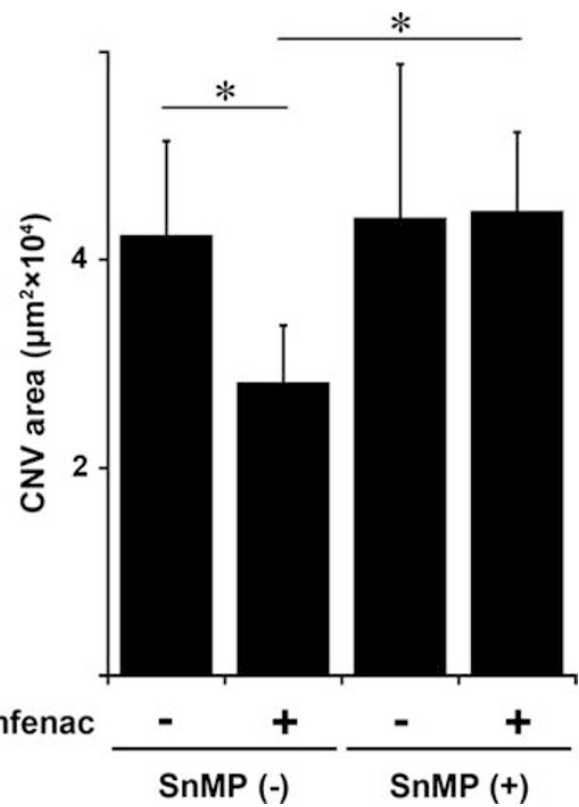

Figure 7 Effects of SnMP on inhibition of bromfenac over CNV size were studied. Topical bromfenac decreased the size of CNV compared with the control (bromfenac rat vs control rat. ${ }^{*} P<0.001$ or bromfenac rat $v s$ bromfenac + SnMP rat; $\left.{ }^{*}<<0.001\right)$. This inhibitory effect was diminished by an inhibitor of HO-1 SnMP (control rat vs bromfenac + SnMP rats; $P=0.923$ ). On the other hand, SnMP itself did not have any significant effect on CNV size. The corrected significant $P$-value (Mann-Whitney $U$-test) was defined as 0.0125 (0.05/4 comparisons) after Bonferroni correction. $n=20$ (PC spots of five rats). Data were expressed as mean \pm s.e.m.

It should be noted that there are other mechanisms to protect the retina from oxidative stress. Qin et $a l^{47}$ showed that cyclopentenone 15-deoxy-delta ${ }^{12,14}$-prostaglandin $\mathrm{J} 2$ protects RPE cells from oxidative injury. Although this mechanism is not evaluated in the present study, it is highly probable that these factors as a whole resulted in the present phenomenon.

There are different kinds of NSAIDs available. Each has different characteristics related to ocular penetration and inhibitory activity of COXs. For example, topical administration of $0.1 \%$ nepafenac inhibits the synthesis of PGs in the retina-choroid by $55 \%$ for $4 \mathrm{~h}^{48}$ Although, topical bromfenac has good ocular penetration and reaches a sufficient level in the retina and choroid, the inhibitory activity of bromfenac on either COX-1 or COX-2 was stronger than nepafenac or dicrofenac. ${ }^{49,50}$ In our pilot study, we tested several different NSAIDs and found that topical bromfenac had a sufficient inhibitory effect on CNV in rat, as expected. Therefore, we chose bromfenac for the present study. But, it should be noted that the present results can be applied to bromfenac.

The present study has limitations. The present CNV model does not perfectly reflect clinical conditions. Certainly AMD or high myopia is a chronic and long-lasting disease. On the other hand, the present model is an acute wound-healing 
a

Bromfenac
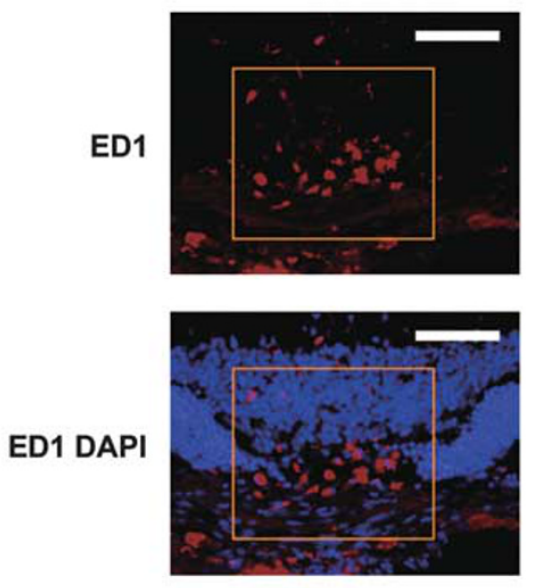

SnMP (-)
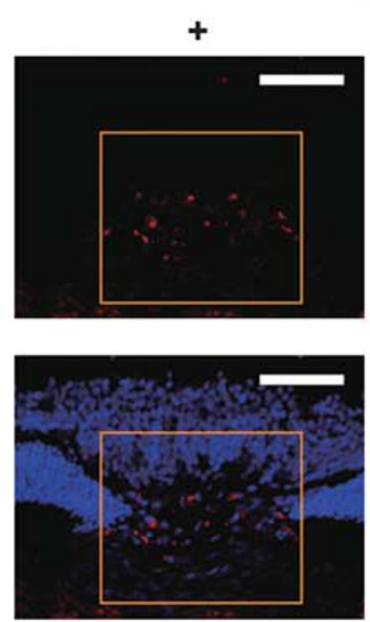
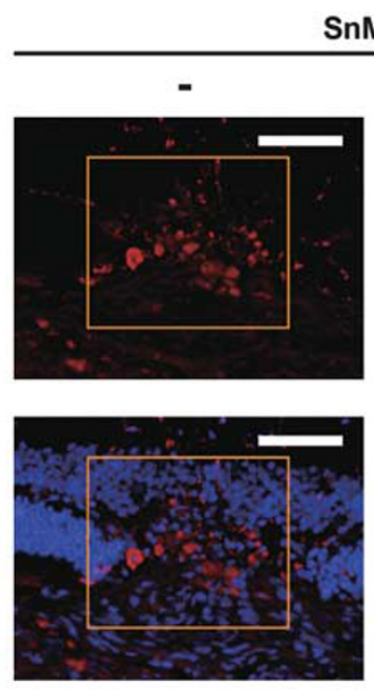

b

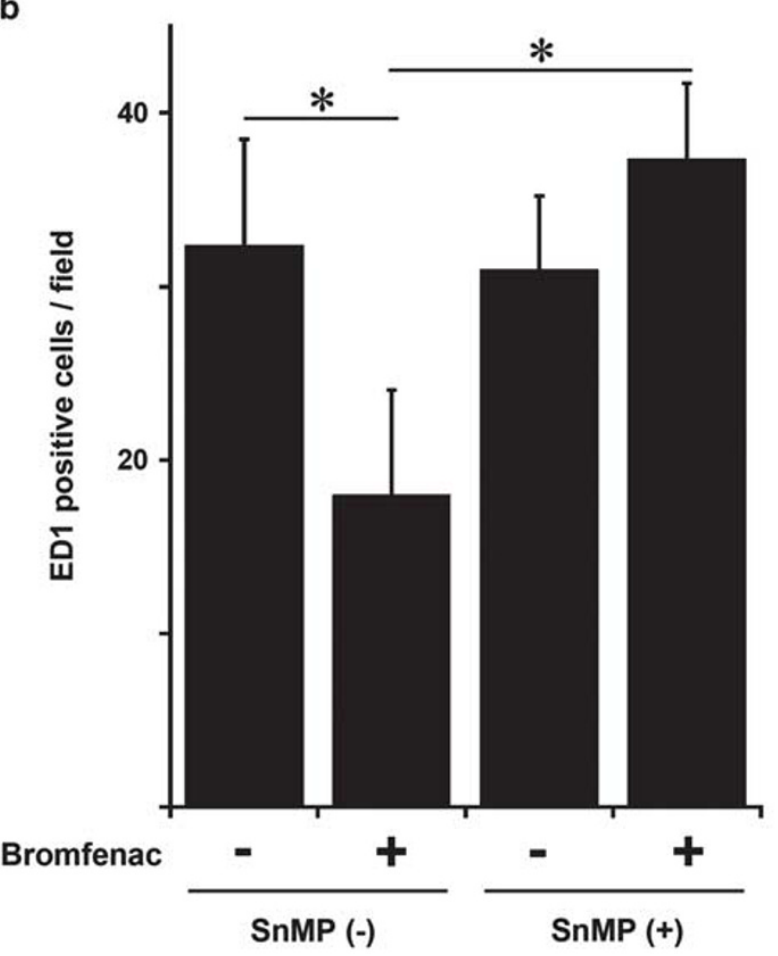

Figure 8 The number of infiltrating ED1-positive macrophages in CNV lesions was examined. (a) Representative images of rat CNV lesion identified by immunofluorescence with anti-ED1 antibody (red) and DAPI (blue). Scale bars: $150 \mu \mathrm{m}$ (b). The number of ED1-positive macrophage infiltration expressed mean \pm s.e.m. cells/field. In the group that received intraperitoneal PBS, infiltration of macrophage was decreased more significantly in bromfenac-treated rats than saline-treated rats $\left({ }^{\star} P<0.01\right)$. Intraperitoneal injections of SnMP reversed this effect and significantly increased macrophage infiltration $\left({ }^{\star} P<0.01\right)$. There was no significant change with macrophage infiltration in saline eye drop-treated rats $(P=0.074) . n=10$. The corrected significant $P$-value (MannWhitney $U$-test) was defined as 0.0125 after Bonferroni correction. Square indicates CNV lesion.

model rather than a chronic disease model. Nonetheless, $\mathrm{CNV}$ in humans occurs in a similar manner to angiogenesis processes in acute wound healing and the present results will help an understanding of the clinical CNV. The second is that we measured the protein level of $\mathrm{HO}-1$, but not its activity. The amount of protein does not necessarily reflect its biological activity. But the fact that an inhibitor of HO-1 reversed the effects of bromfenac indicates that HO-1 is likely to have played a major role in inhibiting $\mathrm{CNV}$ by bromfenac. The third is the treatment efficacy of NSAIDs. The current intravitreous anti-VEGF therapy is so potent for inhibiting $\mathrm{CNV}$ that there may be concerns that any new treatment will hardly improve on the current anti-VEGF therapy. However, complete blocking of VEGF might be potentially harmful 


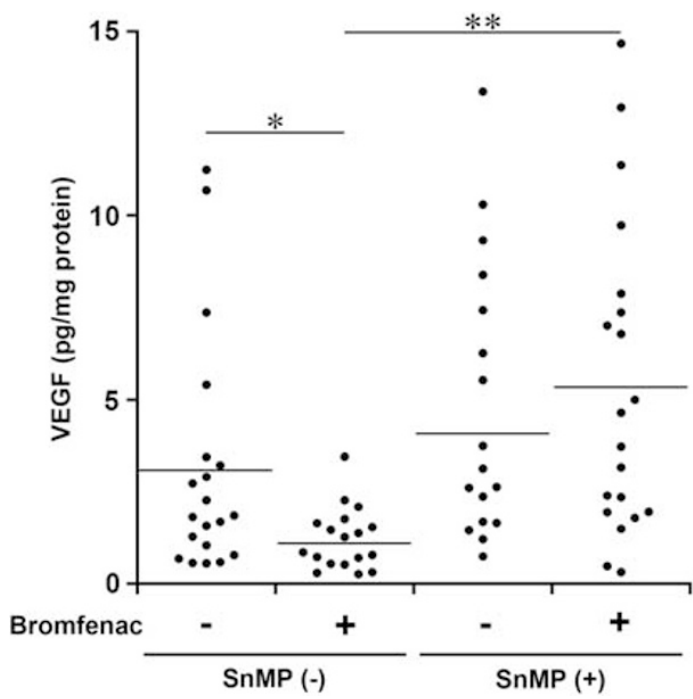

Figure 9 VEGF level of intraocular fluid in each eye was plotted. Analysis of intraocular fluid using ELISA showed that intraocular VEGF level was lower in bromfenac-treated rat $\left({ }^{\star} P<0.01\right)$. Additional injection of SnMP increased intraocular VEGF level as high as in control CNV rats $(* * P<0.001)$. No significant difference resulted from intraperitoneal SnMP alone. Each group contained 20 samples from 20 eyes $(n=20)$. Mean value of each group was expressed by a line. The corrected significant $P$-value (Mann-Whitney $U$-test) was defined as 0.0125 after Bonferroni correction.

after a long period. ${ }^{7,10}$ Topical NSAIDs had therapeutic effects on CNV in this study. Because it has such a potentially neuroprotective effect, combination therapy with an antiVEGF drug may be very advantageous for patients. Combination therapy is found to be more effective, but is less likely to result in drug resistance than mono-therapy in the $t$ reatment of tumor angiogenesis. ${ }^{51}$ In addition, repeated intravitreal injections were necessary for the majority of patients to maintain this level of benefit. ${ }^{4,5}$ Intravitreal injections can be physically uncomfortable, and they expose the patient to a number of potential vision-threatening complications such as intraocular infection. Topical administration of a drug that has the capacity to substantially reduce $\mathrm{CNV}$ would be a promising advance in the development of therapies for neovascular eye diseases. Finally, there was a technical problem in this study. RT-PCR might be more suitable for objective quantification of invading macrophages. We performed RT-PCR using a primer for macrophage; however, no reproducible data were obtained (data not shown). The results were strongly affected by the size of photocoagulation spot or sampling biases. This limitation should be also noted.

In conclusion, the present study showed a new mechanism of NSAIDs for inhibiting neovascularization of the choroid. Topical NSAIDs would be beneficial for the treatment of $\mathrm{CNV}$ not only because of its anti-angiogenic effect but also its potential anti-stress effect. Because the $\mathrm{CNV}$ model can be a mirror for other angiogenic diseases in the central nervous system, NSAIDs could be studied more widely and pro- foundly as a candidate therapy for these disease conditions (Supplementary Figure 1).

Supplementary Information accompanies the paper on the Laboratory Investigation website (http://www.laboratoryinvestigation.org)

\section{ACKNOWLEDGEMENTS}

This work was supported by a grant from the Research Committee on Chorioretinal Degeneration and Optic Atrophy, Ministry of Health, Labor, and Welfare, Tokyo, Japan; and by a Grant-in-Aid for Scientific Research from the Ministry of Education, Science, and Culture of the Japanese Government, Tokyo, Japan.

\section{DISCLOSURE/CONFLICT OF INTEREST}

The authors declare no conflict of interest.

1. Bressler NM, Bressler SB, Fine SL. Age-related macular degeneration. Surv Ophthalmol 1988;32:375-413.

2. Soubrane G. Choroidal neovascularization in pathologic myopia: recent developments in diagnosis and treatment. Surv Ophthalmol 2008;53:121-138.

3. Cohen SY, Laroche A, Leguen Y, et al. Etiology of choroidal neovascularization in young patients. Ophthalmology 1996;103: 1241-1244.

4. TAP study group. Photodynamic therapy of subfoveal choroidal neovascularization in age-related macular degeneration with verteporfin: one-year results of 2 randomized clinical trials-TAP report. Treatment of age-related macular degeneration with photodynamic therapy (TAP) Study Group. Arch Ophthalmol 1999;117:1329-1345.

5. Rosenfeld PJ, Brown DM, Heier JS, et al. Ranibizumab for neovascular age-related macular degeneration. $\mathrm{N}$ Engl J Med 2006;355:1419-1431.

6. Nishijima K, Ng YS, Zhong L, et al. Vascular endothelial growth factor-A is a survival factor for retinal neurons and a critical neuroprotectant during the adaptive response to ischemic injury. Am J Pathol 2007;171:53-67.

7. Robinson GS, Ju M, Shih SC, et al. Nonvascular role for VEGF: VEGFR-1, 2 activity is critical for neural retinal development. FASEB J 2001;15:1215-1217.

8. Murakami $Y$, Ikeda $Y$, Yonemitsu $Y$, et al. Inhibition of choroidal neovascularization via brief subretinal exposure to a newly developed lentiviral vector pseudotyped with Sendai viral envelope proteins. Hum Gene Ther 2010;21:199-209.

9. Saint-Geniez M, Kurihara T, Sekiyama E, et al. An essential role for RPEderived soluble VEGF in the maintenance of the choriocapillaris. Proc Natl Acad Sci USA 2009;106:18751-18756.

10. Rosenfeld PJ, Shapiro H, Tuomi L, et al. Characteristics of patients losing vision after 2 years of monthly dosing in the phase III ranibizumab clinical trials. Ophthalmology 2011;118:523-530.

11. Sakamoto $T$, Soriano $D$, Nassaralla $J$, et al. Effect of intravitreal administration of indomethacin on experimental subretinal neovascularization in the subhuman primate. Arch Ophthalmol 1995; 113:222-226.

12. Takahashi $H$, Yanagi $Y$, Tamaki $Y$, et al. COX-2-selective inhibitor, etodolac, suppresses choroidal neovascularization in a mice model. Biochem Biophys Res Commun 2004;325:461-466.

13. Takahashi K, Saishin Y, Saishin Y, et al. Topical nepafenac inhibits ocular neovascularization. Invest Ophthalmol Vis Sci 2003;44:409-415.

14. Yanni SE, Clark ML, Yang R, et al. The effects of nepafenac and amfenac on retinal angiogenesis. Brain Res Bull 2010;81:310-319.

15. Kim SJ, Toma HS. Inhibition of choroidal neovascularization by intravitreal ketorolac. Arch of Ophthalmol 2010;128:596-600.

16. Kim SJ, Toma HS, Barnett JM, Penn JS. Ketorolac inhibits choroidal neovascularization by suppression of retinal VEGF. Exp Eye Res 2010;91:537-543.

17. Wilson HL, Schwartz DM, Bhatt HR, et al. Statin and aspirin therapy are associated with decreased rates of choroidal neovascularization among patients with age-related macular degeneration. Am J Ophthalmol 2004;137:615-624. 
18. Rezaei KA, Toma $\mathrm{H}$, Cai J, et al. Reduced choroidal neovascular membrane formation in cyclooxygenase-2 null mice. Invest Ophthalmol Vis Sci 2010;52:701-707.

19. Tegeder I, Pfeilschifter J, Geisslinger G. Cyclooxygenase-independent actions of cyclooxygenase inhibitors. FASEB J 2001;15:2057-2072.

20. Ponka P. Cell biology of heme. Am J Med Sci 1999;318:241-256.

21. Maines MD. The heme oxygenase system: a regulator of second messenger gases. Annu Rev Pharmacol Toxicol 1997;37:517-554.

22. Brouard S, Otterbein LE, Anrather J, et al. Carbon monoxide generated by heme oxygenase 1 suppresses endothelial cell apoptosis. J Exp Med 2000;192:1015-1026.

23. Alcaraz MJ, Habib A, Créminon C, et al. Heme oxygenase-1 induction by nitric oxide in RAW 264.7 macrophages is upregulated by a cyclooxygenase-2 inhibitor. Biochim Biophys Acta 2001;1526:13-16.

24. Hou CC, Hung SL, Kao SH, et al. Celecoxib induces heme-oxygenase expression in glomerular mesangial cells. Ann NY Acad Sci 2005; 1042:235-245.

25. Nascimento-Silva V, Arruda MA, Barja-Fidalgo C, et al. Novel lipid mediator aspirin-triggered lipoxin A4 induces heme oxygenase-1 in endothelial cells. Am J Physiol Cell Physiol 2005;289:C557-C563.

26. Grosser N, Abate A, Oberle S, et al. Heme oxygenase-1 induction may explain the antioxidant profile of aspirin. Biochem Biophys Res Commun 2003;308:956-960.

27. Cantoni L, Valaperta $R$, Ponsoda $X$, et al. Induction of hepatic heme oxygenase- 1 by diclofenac in rodents: role of oxidative stress and cytochrome P-450 activity. J Hepatol 2003;38:776-783.

28. Arimura N, Ki-i Y, Hashiguchi T, et al. Intraocular expression and release of high-mobility group box 1 protein in retinal detachment. Lab Invest 2009;89:278-289.

29. Otsuka H, Arimura N, Sonoda S, et al. Stromal cell-derived factor-1 is essential for photoreceptor cell protection in retinal detachment. Am J Pathol 2010;177:2268-2277.

30. Fujimoto T, Sonoda KH. Choroidal neovascularization enhanced by Chlamydia pneumoniae via Toll-like receptor 2 in the retinal pigment epithelium. Invest Ophthalmol Vis Sci 2010;51:4694-4702.

31. Honda M, Sakamoto T, Ishibashi T, et al. Experimental subretinal neovascularization is inhibited by adenovirus-mediated soluble VEGF/flt-1 receptor gene transfection: a role of VEGF and possible treatment for SRN in age-related macular degeneration. Gene Ther 2000;7:978-985

32. Aburaya M, Tanaka K-I, Hoshino T, et al. Heme oxygenase-1 protects gastric mucosal cells against non-steroidal anti-inflammatory drugs. J Biol Chem 2006;281:33422-33432.

33. Jones MK, Wang H, Peskar BM, et al. Inhibition of angiogenesis by nonsteroidal anti-inflammatory drugs: insight into mechanisms and implications for cancer growth and ulcer healing. Nat Med 1999;5: 1418-1423.

34. Jones MK, Szabó IL, Kawanaka H, et al. von Hippel Lindau tumor suppressor and HIF-1alpha: new targets of NSAIDs inhibition of hypoxia-induced angiogenesis. FASEB J 2002;16:264-266.

35. Ferrara N. Vascular endothelial growth factor and the regulation of angiogenesis. Recent Prog Horm Res 2000;55:15-35.
36. Tsutsumi $\mathrm{C}$, Sonoda $\mathrm{KH}$, Egashira $\mathrm{K}$, et al. The critical role of ocularinfiltrating macrophages in the development of choroidal neovascularization. J Leukoc Biol 2003;74:25-32.

37. Ghosh S, May MJ, Kopp EB. NF-kappa B and Rel proteins: evolutionarily conserved mediators of immune responses. Annu Rev Immunol 1998; 16:225-260.

38. Jaiswal AK. Nrf2 signaling in coordinated activation of activation of antioxidant gene expression. Free Radic Biol Med 2004;36: 1199-1207.

39. Kaspar JW, Niture SK, Jaiswal AK. Nrf2:INrf2 (Keap1) signaling in oxidative stress. Free Radic Biol Med 2009;47:1304-1309.

40. Healy ZR, Lee NH, Gao X, et al. Divergent responses of chondrocytes and endothelial cells to shear stress: cross-talk among COX-2, the phase 2 response, and apoptosis. Proc Natl Acad Sci USA 2005;102: 14010-14015.

41. Bussolati $B$, Ahmed A, Pemberton $\mathrm{H}$, et al. Bifunctional role for VEGFinduced heme oxygenase-1 in vivo: induction of angiogenesis and inhibition of leukocytic infiltration. Blood 2004;103:761-766.

42. Dulak J, Loboda A, Zagórska A, Józkowicz A. Complex role of heme oxygenase-1 in angiogenesis. Antioxid Redox Signal 2004;6: 858-866.

43. Bussolati B, Mason JC. Dual role of VEGF-induced heme-oxygenase-1 in angiogenesis. Antioxid Redox Signal 2006;8:1153-1163.

44. Mandal MN, Patlolla JM, Zheng $L$, et al. Curcumin protects retinal cells from light-and oxidant stress-induced cell death. Free Radic Biol Med 2009;46:672-679.

45. Shyong MP, Lee FL, Hen $\mathrm{WH}$, et al. Viral delivery of heme oxygenase-1 attenuates photoreceptor apoptosis in an experimental model of retinal detachment. Vision Res 2008;48:2394-2402.

46. Sun $\mathrm{MH}, \mathrm{Su}$ Pang $\mathrm{JH}$, Chen $\mathrm{SL}$, et al. Retinal protection from acute glaucoma-induced ischemia-reperfusion injury through pharmacological induction of heme oxygenase- 1 by cobalt protoporphyrin. Invest Ophthalmol Vis Sci 2010;51:4798-4808.

47. Qin S, McLaughlin AP, De Vries GW. Protection of RPE cells from oxidative injury by 15-deoxy-delta12,14-prostaglandin $\mathrm{J} 2$ by augmenting GSH and activating MAPK. Invest Ophthalmol Vis Sci 2006;47: 5098-5105.

48. Gamache DA, Graff G, Brady MT, et al. Nepafenac, a unique nonsteroidal prodrug with potential utility in the treatment of traumainduced ocular inflammation. I: assessment of anti-inflammatory efficacy. Inflammation 2000;24:357-370.

49. Isaka M, Inada K, Tsutsumi S, et al. Ocular tissue distribution in rabbit after instillation of bromfenac sodium ophthalmic solution. Drug Metabol Pharmacokinet 1999;14:32-41.

50. Kida T, Ogawa T, McNamara TR, et al. Evaluations of the human COX-1 and COX-2 inhibition for amfenac, bromfenac, ciclofenac, and ketorolac. Annu Meet Guide Abstr Am Coll Clin Pharm 2007; (Suppl):274.

51. Abdollahi A, Folkman J. Evading tumor evasion: current concepts and perspectives of anti-angiogenic cancer therapy. Drug Resist Updat 2010;13:16-28. 